\title{
Diversity Analysis in Linseed (Linum usitatissimum L.)
}

\author{
Satyendra Kumar, Aarti Sharma*, Purushottam and M.P. Chauhan \\ Department of Genetics and Plant Breeding, Narendra Deva University of Agriculture and \\ Technology, Faizabad-224 229, UP, India \\ *Corresponding author
}

\section{A B S T R A C T}

Keywords

$\mathrm{D}^{2}$ statistics, Linseed, Intercluster, Intra-cluster

Article Info

Accepted:

07 January 2018

Available Online:

10 February 2018
In this experiment 66 linseed genotypes, along with three check varieties (T-397, Mukta and Hira) were analyzed for genetic diversity by Mahalanobis $\mathrm{D}^{2}$ statistics. Presence of diversity pave way for exploitation of genotypes in breeding programme intended to improve yield and yield attributing traits. The cluster analysis grouped 66 linseed genotypes into 9 distinct clusters. Genotypes grouped into cluster II were showed maximum intra-cluster diversity while cluster $\mathrm{V}$ showed minimum intra-cluster diversity. The maximum inter-cluster diversity was observed between cluster VIII and V while minimum inter-cluster diversity was observed between cluster IV and III. From cluster mean value, genotypes in cluster VI, VII and IV deserve consideration for their direct use as parents in hybridization programs to develop high yielding linseed varieties. Thus, hybridization among these cluster pairs is recommended for getting high transgressive segregants in F2 generation.

\section{Introduction}

Linseed is a versatile crop, used for fiber and oil both. Linseed oil has various industrial and medicinal uses (Chauhan et al., 2009).

Linseed has an increasing demand in agro based industries but still the average productivity is very low as compared to other countries, due to lack of high yielding varieties. The major causes behind low production are cultivation of linseed mainly in marginal land coupled with disease, insectpest problems and also poor crop management. Few high yielding varieties of linseed are available, which suffers from various biotic and abiotic stresses.
The studies on variation in the germplasm are very useful for developing high yielding, disease and insect- pest resistant cultivars. The selection of suitable divergent parents for hybridization is required because the cross involving diverse parents offer great possibility of obtaining desirable segregants in the segregating generations (Moll and Robinson, 1962).

With comprehension of aforementioned details, a study on genetic divergence analysis using techniques like Mahalanobis $\mathrm{D}^{2}$ or nonhierarchical were applied to assess genetic variability present in the 66 genotypes along with three check varieties (T-397, Mukta and Hira) used in this experiment. Similar works 
have also been reported by (Payasi, 2000; Diederichsen, 2001; Adugna and Labuschagne, 2004; Mahto, 2004; Begum et al., 2007). Higher the genetic variability more will be the opportunities to expect improvement through appropriate selection procedure(s) (Muhammad et al., 2003). The study indicated that the different clusters showed considerable difference in inter-cluster group means of 10 characters and genotypes having distinctly different mean performance for various characters and were separated into different clusters.

Based on the high inter cluster distance between cluster VI and I, hybridization between genotypes of these two cluster VI (ICAR Sel.-1) and cluster I (L-9, No-314, H660, Lck-87042, NDL-2005-22, GS-335) may produce promising genotypes in segregating generations.

\section{Materials and Methods}

The experimental material comprising 66 linseed germplasm lines along with three checks (T-397, Mukta and Hira) were planted in augmented block design. The experimental field was divided into three blocks of twenty four plots. The checks were distributed randomly in each block. Observations on the following characteristics were recorded on the basis of five plants randomly selected. The analysis of variance for different characters in Augmented Block Design was done according to Federer (1956).

Genetic divergence was studied through Nonhierarchical Euclidean cluster analysis (Beale, 1969; Spark, 1973). According to Beale (1969) each observation in cluster analysis is initially allocated to its closest cluster center. The means of clusters are then calculated and are taken to new cluster centers. The recommended cultural practices were followed to raise a good crop.

\section{Results and Discussion}

The distribution of 66 linseed genotypes in nine clusters is given in (Table 1). Kanchan and Rao (2008) observed nine clusters too while analyzing 90 genotypes. The highest number of genotypes appeared in cluster III which contained 11 entries followed by cluster VI having 10 entries. Cluster VII possess 9 entries, while cluster IX were constituted of 8 lines. Cluster IV having 7 entries. Cluster I and II possessed 6 lines. Cluster VIII having 5lines. Cluster V was represented by 4 entries. The estimates of intra and inter cluster distance for 10 characters are presented in Table 2. The highest intra-cluster distance was observed in case of cluster II (14.53), followed by cluster III (10.88). The lowest intra-cluster distance was noted for cluster V (5.74) followed by cluster VIII (6.85). The maximum inter cluster distance was observed between cluster VIII and V (56.00) followed by cluster VI and V (45.92). The minimum inter-cluster distance was observed between cluster IV and III (13.86) followed by cluster IX and VI (15.38).

Cluster mean for 10 characters are presented in Table 3. The genotypes of cluster VI were responsible for highest cluster mean for days to $50 \%$ flowering (89.64 days) followed by entries of cluster VIII (87.37 days) and cluster IV (85.27 days). The genotypes, with early flowering were concentrated in cluster XI (62.57 days). The highest cluster mean for plant height was observed in case of cluster VIII $(89.60 \mathrm{~cm})$ followed by cluster VII $(74.60 \mathrm{~cm})$. The lowest cluster mean for plant height was found in case of cluster IX (46.53 $\mathrm{cm})$.

Considering the variation in number of primary branches per plant cluster IV (6.14) showed highest mean value while, cluster IX (3.51) had lowest value for number of primary branches per plant. 
Table.1 Clustering pattern of 66 linseed genotypes on the basis of non-hierarchical Euclidean cluster analysis for 10 characters

\begin{tabular}{|c|c|l|}
\hline No. Cluster & No. of Genotype & Genotype \\
\hline $\mathbf{1}$ & 6 & L-9, No-314, H-660, Lck-87042, NDL-2005-22, GS-335. \\
\hline $\mathbf{2}$ & 6 & GEWARGI 1-2, GS-179, No-1536, GS-229, L-67, H-31. \\
\hline $\mathbf{3}$ & 11 & $\begin{array}{l}\text { GS-415, NDL-2005-16, GS-30, NDL-2011-01, NDL-2011-8, NDL- } \\
\text { 2007-12, NDL-2005-34, NDL-2007-03, NDL-2005-23, NDL-2005- } \\
\text { 29, MUKTA. }\end{array}$ \\
\hline $\mathbf{4}$ & $\mathbf{5}$ & H-15, Hy52 RR-9, L-103, L-120, Hyb-603-2, GS-145, Hy-262. \\
\hline $\mathbf{5}$ & 4 & JRF, ICAR, NDL-2005-24, LC-54 \\
\hline $\mathbf{6}$ & 10 & $\begin{array}{l}\text { Kanpur local, NP26 (SR) SK, No-1439, LW-81, H-49, NL-145, GS- } \\
\text { 436, No-3*RR 485, No-349, L-49. }\end{array}$ \\
\hline $\mathbf{7}$ & 9 & L-48, Holden, No-335, L-98, GLC-1-1, GS-53, NDL-2011-09, \\
\hline $\mathbf{8}$ & $\mathbf{G U N A U W A L ~ l o c a l , ~ N o - 4 5 ~}$ \\
\hline $\mathbf{9}$ & $\mathbf{5}$ & KP-45, GS-81, JASIHI -1-3, NDL-2005-17, HIRA. \\
\hline & 8 & N-49, NDL-2007-09, NP-36, GS-361, GS-66, L-107, NDL-2011-02, \\
\hline
\end{tabular}

Table.2 Estimates of average intra and inter- cluster distances for the 9 clusters in linseed

\begin{tabular}{|l|l|l|l|l|l|l|l|l|l|}
\hline & I & II & III & IV & V & VI & VII & VIII & IX \\
\hline I & $\mathbf{1 0 . 7 0 4}$ & 18.686 & 23.087 & 17.684 & 21.929 & 17.942 & 23.640 & 25.454 & 17.312 \\
\hline II & & $\mathbf{1 4 . 5 3 1}$ & 19.286 & 25.399 & 25.489 & 24.060 & 19.000 & 25.272 & 23.273 \\
\hline III & & & $\mathbf{1 0 . 8 8 5}$ & 13.865 & 19.632 & 28.173 & 20.904 & 35.759 & 20.560 \\
\hline IV & & & & $\mathbf{8 . 1 0 1}$ & 17.252 & 25.501 & 24.045 & 37.323 & 21.175 \\
\hline V & & & & & $\mathbf{5 . 7 4 3}$ & 45.926 & 40.941 & 56.007 & 32.777 \\
\hline VI & & & & & & $\mathbf{8 . 3 7 5}$ & 16.350 & 18.839 & 15.384 \\
\hline VII & & & & & & & $\mathbf{8 . 2 0 0}$ & 15.748 & 20.523 \\
\hline VIII & & & & & & & & $\mathbf{6 . 8 5 4}$ & 18.740 \\
\hline IX & & & & & & & & & $\mathbf{8 . 1 2 1}$ \\
\hline
\end{tabular}

Bold figure represent intra-cluster distance

Table.3 Cluster mean of 9 cluster for different characters in linseed

\begin{tabular}{|l|l|l|l|l|l|l|l|l|l|l|}
\hline $\begin{array}{l}\text { Cluster } \\
\text { no. }\end{array}$ & $\begin{array}{l}\text { Days to } \\
\text { 50\% } \\
\text { flowering }\end{array}$ & $\begin{array}{l}\text { Plant } \\
\text { height } \\
\text { (cm) }\end{array}$ & $\begin{array}{l}\text { Primary } \\
\text { branches } \\
\text { /plant }\end{array}$ & $\begin{array}{l}\text { Secondary } \\
\text { branches } \\
\text { /plant }\end{array}$ & $\begin{array}{l}\text { Capsules } \\
\text { /plant }\end{array}$ & $\begin{array}{l}\text { Seeds } \\
\text { /capsules }\end{array}$ & $\begin{array}{l}\text { Biological } \\
\text { yield } \\
\text { /plant }\end{array}$ & $\begin{array}{l}\text { Harvest } \\
\text { index } \\
\text { (\%) }\end{array}$ & $\begin{array}{l}\text { Test } \\
\text { weight } \\
\text { (g) }\end{array}$ & $\begin{array}{l}\text { Seed } \\
\text { yield } \\
\text { /plant }\end{array}$ \\
\hline I & 84.174 & 63.950 & 4.982 & 51.962 & 64.450 & 6.786 & 6.595 & 4.400 & 20.783 & 20.945 \\
\hline II & 68.097 & 51.744 & 4.615 & 44.410 & 60.056 & 6.010 & 6.352 & 5.474 & 23.252 & 23.713 \\
\hline III & 77.982 & 65.945 & 4.588 & 29.073 & 44.648 & 6.764 & $7.039 * *$ & 4.596 & 21.568 & 21.075 \\
\hline IV & 85.278 & 67.658 & $6.149 * *$ & 72.567 & 83.621 & 6.511 & 6.179 & 5.870 & 22.654 & 25.898 \\
\hline V & 77.611 & 68.667 & 4.878 & 42.067 & 73.033 & 6.911 & 6.941 & 5.257 & 23.467 & 21.108 \\
\hline VI & $89.644 * *$ & 56.067 & 3.778 & 16.933 & $31.067 *$ & 6.711 & 6.982 & $3.436 *$ & $18.077 *$ & 19.251 \\
\hline VII & 81.778 & 74.600 & 5.511 & $100.400 * *$ & $93.400^{* *}$ & 5.578 & 6.556 & $6.552^{* * *}$ & 22.673 & $28.744 * *$ \\
\hline VIII & $87.378 *$ & $89.600 * *$ & 6.111 & $27.800 *$ & 48.800 & $8.978^{* *}$ & $6.176^{*}$ & 4.292 & $24.133 * *$ & $16.594 *$ \\
\hline IX & 62.578 & $46.533 *$ & $3.511^{*}$ & 29.467 & 39.133 & $4.511^{*}$ & 6.552 & 3.882 & 22.090 & 18.334 \\
\hline
\end{tabular}

Minimum value *

Maximum value ** 
The highest cluster mean for number of secondary branches per plant was observed in case of cluster VII (100.40) followed by cluster IV (72.56) while genotypes with very low number of secondary branches per plant were found to be grouped in cluster VI (16.93). The highest cluster mean for number of capsules per plant was exhibited by cluster VII (93.40) followed by cluster IV (83.62), while the lowest cluster mean of capsules per plant was produced by entries of cluster VI (31.06).The genotypes occurring in cluster VIII (8.97) and cluster V (6.91) showed highest mean for number of seed per capsule while the genotypes of cluster IX (4.51) were responsible for lowest means for number of seed per capsule. Cluster VIII (24.13g) followed by cluster $\mathrm{V} \quad(23.46 \mathrm{~g})$ were comprised of entries which produced highest mean for biological yield per plant. The lowest cluster mean for biological yield per plant was observed for cluster VI (18.07g). The highest cluster mean for seed yield per plant was observed in case of cluster VII $(6.55 \mathrm{~g})$ followed by cluster IV $(5.87 \mathrm{~g})$. The lowest cluster mean for seed yield per plant was exhibited by cluster VI (3.43g)

The nine clusters in the aforesaid divergence analysis contained genotypes of heterogeneous origin frequently. The highest inter-cluster distance was observed between cluster VI and I, followed by cluster VI and III. The lowest inter-cluster distance was observed between cluster VIII and VII followed by cluster VIII and IV, which indicated that genotypes present in these cluster pairs were genetically close to each other. The crosses between genotypes belonging to the clusters separated by low inter cluster distances are unlikely to generate promising recombinants in segregating generations. Ananda and Murty, (1968) also proposed hybridization between lines belonging to clusters separated by large inter cluster distance in linseed. The intra-cluster group mean for 10 characters revealed considerable differences between clusters in respect of cluster means (Table 3). An examination of the estimates of within and between cluster diversity presented by intra and inter cluster $\mathrm{D}^{2}$ values revealed that the genotypes of same cluster had little divergence from each other with respect to aggregate effect of 10 characters under study (Table 2). Therefore, the chances of obtaining good recombinants in segregating generations by crossing the members of same cluster are very low. It is, therefore, suggested that crosses should be attempted between the genotypes belonging to clusters separated by large inter-cluster distance. This finding is in agreement with the report advocating lack of definite relationship between genetic and geographic diversity in linseed (Murty and Ananda, 1968; Jeswani et al., 1970; Asthana and Pandey, 1980; Srivastava et al., 2009; Chauhan et al., 2013).

\section{References}

Adugna, W. and Labuschange, M.T. 2004. Diversity analysis in Ethiopian and some exotic collection of linseed. $S$. African J. Plant and Soil. 21(1): 53-58.

Ananda, I.I. and Murty, B.R. 1968. Genetic divergence and hybrid performance in linseed. Indian J. Genet.28: 178-185.

Asthana, A.N. and Pandey, V.K. 1980. Genetic divergence in Linseed. Indian J. Genet.40 (10): 247-250.

Beale, E.M.L. 1969. Euclidean cluster analysis. A paper contributed to $37^{\text {th }}$ session of International Statistical Institute.

Begum, H., Alam, A.K.M.M., Chawdhury, M.J.A. and Hossain, M.I. 2007. Genetic divergence in linseed (Linum usitatissimum L.). Inter. J. Sustain. Crop Prod., 2(1): 4-6.

Chauhan, M.P., S. Singh and A. K. Singh 2009. Post-Harvest Uses of Linseed. J. 
Hum Ecol, 28(3): 217-219.

Chauhan, M. P., Singh, A. K. and Singh V. 2013. Genetic diversity within a range of varieties elite lines and land races of linseed. J. Prog. Agric., 4 (2): 68-71

Diederichsen, A. 2001. Comparison of genetic diversity of flax (Linum usitatissimum L.) between Canadian cultivars and a world collection. Plant Breeding.120 (4): 360-362.

Jeswani, L.M., Murty, B.R. and Mehra, R.B. 1970. Divergence in relation to geographical origin in a world collection of linseed. Indian J. Genet., 30: 11-25.

Kanchan, K. and Rao S.S. 2008. Genetic divergence in linseed (Linum usitatissimum L.) Mysore J. Agric. Sci., 42 (1):15-19.

Mahto, J.L. 2004. Genetic divergence and stability analysis in rainfed linseed. $J$. Res., ANGRAU. 32 (4): 39-43.
Moll, R.H. and Robinson, R.F. 1962. Heterosis and genetic diversity in variety crosses of maize. Crop Sci. 2: 197-209.

Muhammad, A., Mahmood, T., Anwar, M. Muhammad, A., Muhammad, S. and Jafar, S. 2003. Linseed improvement through genetic variability, correlation and path coefficient analysis. Int. J. Agric. Biol. 5(3): 303-305.

Payasi, S. K. 2000. Genetic divergence in linseed. Crop Research (Hisar).19 (1): 158-161.

Spark, D.N. 1973. Euclidean cluster analysis, Algorithm As-58.Applied Statistics, 22: 126-130.

Srivastava, R. L., Singh, H.C., Malik, K.H. and Prakash, O. 2009. Genetic divergence in linseed, Linum usitatissimum L. under salt stress condition. Journal of Oilseeds Research. 26 (2): 159-161.

\section{How to cite this article:}

Satyendra Kumar, Aarti Sharma, Purushottam and Chauhan, M.P. 2018. Diversity Analysis in Linseed (Linum usitatissimum L.). Int.J.Curr.Microbiol.App.Sci. 7(02): 790-794.

doi: https://doi.org/10.20546/ijcmas.2018.702.100 